\title{
Calculation Model of Wind Energy Output Based on Capacity Factor
}

\author{
Xinli Zhang ${ }^{1, a}$, Limin Jia ${ }^{1, b}$, Chenyu Wang ${ }^{1, c}$ \\ ${ }^{1}$ Business School of Sichuan University, China, 610064 \\ a504161363@qq.com, b492561232@qq.com, '826282215@qq.com
}

Keywords: wind; capacity factor; energy output

\begin{abstract}
The capacity factor shows the annual energy output efficiency of a wind turbine and can be used to evaluate the operation performance of the wind turbine. In this paper, we use the capacity factor to study the operation performance of wind turbines. Firstly, based on the wind speed conditions and the performance parameters of wind turbine devices, the revenue and cost of a wind energy project are calculated. The calculation formula of economic capacity factor is derived by breakeven analysis of the revenue and cost. Secondly, considering different machine types and wind speeds, a simplified physical calculation formula of physical capacity factor is developed. Finally, a case study with actual data in a specified area is presented. The values of economic and physical capacity factors are provided. The differences between them are discussed in detail. The relationship between the mean wind speed and capacity factor is discussed. The result provides a new quantitative basis for selecting wind turbine and farm which are suitable for territorial wind speed conditions.
\end{abstract}

\section{Introduction}

Nowadays, the proportion of renewable energy resources is increased in China. Wind energy became a fast growing alternative energy source. "The China wind power development roadmap 2020" indicates that by the year 2020 the installed capacity of wind power will reach 0.2 billion $\mathrm{kW}$. According to this national planning, the stake electrovalence of wind power will be equivalent to that of coal power by the year 2020.The stake state electrovalence of wind power will decrease from 0.6 $¥ / \mathrm{kWh}$ to $0.4 ¥ / \mathrm{kWh}$. Therefore, in order to ensure the price competitiveness, improving the investment efficiency and operation benefit of wind energy project is a key problem.

There are some researches on the location selection of wind power farms, type selection of wind turbines and calculation model of wind energy output. Wenjun Zhang et. al ${ }^{[1]}$ claim that the generated energy by wind is related to the wind energy potential and the performance of wind turbines. The generated energy is closely related to economic benefits. Paper [2] assesses the wind energy potential for a given location and selects the wind turbine by using costs of kWh wind-generated electricity. Paper [3] uses chance constrained programming and montecarlo method to obtain the optimal installed capacity by considering the maximum economic benefit of wind farms. Paper [4] provides the optimum selection of rated wind speed for wind turbine, and presents that the increasing wind turbine diameter can increase the economic benefit. These papers propose the influence of wind speed condition and wind turbine performance on the economic benefit. The indexes used in these papers are mostly net present value and the cost of $\mathrm{kWh}$ wind-generated electricity. Paper [5] proposes the properties of capacity factor. A higher capacity factor value shows that the exploitation of the wind potential for the specific site is better. Paper [6] suggestes that the capacity factor depends on the site of wind energy farm and the machine model.

This paper calculates the revenue and cost of the wind energy project based on the existing literatures, obtains the economic capacity factor by breakeven analysis based on the influencing factors of the capacity factor, and estimeats the physical capacity factor at different machine models and different wind speeds. On this basis, this paper presents a case study to derive the relationship between the mean wind speed and capacity factor. The result provides a new quantitative basis for the wind turbine selection and wind farm location selection. 


\section{Methodology}

Before modeling, we made the following assumptions : the cost and revenue which we estimate are annual values. The annual mean of wind speed is calcated by the wind speed at the certain hub height.

The capacity factor. The capacity factor $\left(C_{F}\right)$ is the ratio between the power produced by wind turbines and the total power of the full capacity. It can be expressed as ${ }^{[6]}$ :

$$
C_{F}=E_{t} / t P_{R}
$$

where $t$ is the running time of wind turbine, $E_{t}$ is the generated energy for $t$ time, $P_{R}$ is the rated power of the wind turbine.

Rated power and cost. The cost of the wind energy project consists of the initial investment cost $\left(C_{i}\right)$ and the operation and maintenance costs $\left(C_{o m}\right) . C_{i}$ can be calculated as follows ${ }^{[7]}$

$$
C_{i}=\left(1+\lambda_{1}\right) P_{R} \times C_{P R}
$$

where $P_{R}$ and $C_{P R}$ are the rated power of wind turbines and specific costs , and $\lambda_{1}$ is the ratio of other initial costs.

The operation and maintenance costs of wind energy consist of salary, depreciation costs and maintenance costs. The salary $\left(C_{S}\right)$ can be expressed as ${ }^{[7,8]}$.

$$
C_{s}=n C_{e p} P_{R}
$$

Where $n$ is the staff number of unit rated power, $C_{e p}$ is the annual average salary of per staff, and $P_{R}$ is the rated power of the wind turbine.

The depreciation costs $\left(C_{D}\right)$ can be determined by the straight-line depreciation method as ${ }^{[7,8]}$ :

$$
C_{D}=\frac{C_{w t}(1-S)}{T}=\frac{P_{R} \times C_{P R}(1-S)}{T}
$$

where $S$ and $T$ are, respectively, the ratio of remaining value and depreciation life. $C_{w t}$ is the wind turbine cost as seen in Eq. 2.

The maintenance cost $\left(C_{M}\right)$ can be expressed as a percentage of the initial investment cost as Eq. $5^{[7,8]}$. where $\lambda_{2}$ is the ratio of the maintenance cost to the initial investment cost .

$$
C_{m}=\lambda_{2} C_{i}=\lambda_{2}\left(1+\lambda_{1}\right) \times P_{R} \times C_{P R}
$$

The annual cost of operation period $(C)$ can be determined by the following equation:

$$
C=C_{w}+C_{D}+C_{m}=P_{R} \times\left[n C_{e p}+\frac{C_{P R}(1-S)}{T}+\lambda_{2}\left(1+\lambda_{1}\right) C_{P R}\right]
$$

Let $\mu_{1}$ be the following expression Eq.7. Finally, the cost of wind energy can be expressed as Eq.8.

$$
\begin{aligned}
& \mu_{1}=n C_{e p}+\frac{C_{P R}(1-S)}{T}+\lambda_{2}\left(1+\lambda_{1}\right) C_{P R} \\
& C=\mu_{1} P_{R}
\end{aligned}
$$

Revenue and profits. The revenue of wind energy project $(R)$ is mainly the power selling income which can be expressed as Eq. $9^{[8]}$. Where $P_{e}$ is the stake electrovalence of wind energy $(\$ / \mathrm{kWh}), E_{t}$ is the production capability for $\mathrm{t}$ time $(\mathrm{kWh})$.

$$
R=P_{e} \times E_{t}
$$

The profit of wind energy project can be determined by the gap between the cost and the revenue, which is denoted as follows:

$$
P=R-C=P_{e} \times E-\mu_{1} P_{R}
$$

The capacity factor under breakeven analysis. In the breakeven analysis, the revenue and cost are equivalent. Substitute Eq.10 into Eq.1, the capacity factor under breakeven analysis $\left(E C_{F}\right)$ can be calculated as Eq.11. Let $E C_{F}$ be the economic capacity factor.

$$
E C_{F}=\mu_{1} /\left(t P_{e}\right)
$$

The physical capacity factor. The capacity factor can be calculated by the mean wind speed of wind farms and the power curve of wind turbines ${ }^{[8]}$. Let this capacity factor be the physical capacity 
factor $\left(P C_{F}\right)$. In this case, the physical generated energy $\left(P E_{t}\right)$ can be expressed as follows:

$P E_{t}=t \times P_{V m}$

where $P_{v m}$ is the wind generator power output at the mean wind speed.

Substitute Eq. 12 into Eq.1, $P C_{F}$ can be expressed as:

$$
P C_{F}=\frac{P E_{t}}{t P_{R}}=\frac{P_{V m}}{P_{R}}=\left\{\begin{array}{cc}
1 & \text { else } \\
\frac{1}{V_{R}^{3}-V_{I}^{3}} V_{m}^{3}-\frac{V_{I}^{3}}{V_{R}^{3}-V_{I}^{3}} V_{I} \leq V_{m} \leq V_{R} \\
1 & V_{R} \leq V_{m} \leq V_{O}
\end{array}\right.
$$

where $V_{R}$ is the rated speed, $V_{I}$ is the cut-in speed, $V_{O}$ is the cut-out speed and $P_{R}$ is the rated power.

\section{Case analysis}

The parameter values are essential in calculating $E C_{F}$ and $P C_{F}$ as shown in Table 1 . Some parameter values are referred to the existing literature. Others are estimated based on the economic condition.

Table 1 The parameter values

\begin{tabular}{l|l|l|l}
\hline The parameter name & The specific value & The parameter name & The specific value \\
\hline$C_{P R}(\Psi / \mathrm{Kw})$ & $5100^{[7]}$ & $\lambda_{1}$ & $30 \%^{[7]}$ \\
$n$ & 0.003 & $\lambda_{2}$ & $6 \%^{[7]}$ \\
$C_{e p}(¥)$ & 20000 & $t(\mathrm{~h})$ & 8760 \\
$S$ & $10 \%{ }^{[7]}$ & $P_{e}(\Psi / \mathrm{kWh})$ & $0.51^{[8]}$ \\
$T$ (year) & $20^{[7]}$ & \\
\hline$E C_{F}$ can be calculated based on Table 1 and Eq.11 as follows: \\
$E C_{F}=0.154$
\end{tabular}

Wind turbine models with three sizes and rated power ranging from $1000 \mathrm{~kW}$ to $2500 \mathrm{~kW}$ are chosen from different manufactures to simulate their $P C_{F}$. The specification of selected wind turbines are given in Table 2.

Table 2 Specification of considered wind turbines

\begin{tabular}{lllll}
\hline $\begin{array}{l}\text { Wind turbine } \\
\text { Model }\end{array}$ & $\begin{array}{c}\text { Cut-in speed } \\
(\mathrm{m} / \mathrm{s})\end{array}$ & $\begin{array}{c}\text { Cut-out speed } \\
(\mathrm{m} / \mathrm{s})\end{array}$ & $\begin{array}{c}\text { Rated speed } \\
(\mathrm{m} / \mathrm{s})\end{array}$ & $\begin{array}{l}\text { Rated power } \\
(\mathrm{kW})\end{array}$ \\
\hline 1 & 3.5 & 25 & 13 & 2500 \\
2 & 4 & 23 & 14 & 2000 \\
3 & 3 & 25 & 15 & 1000 \\
\hline
\end{tabular}

The mean wind speed between cut-in speed and rated speed is chosen to calculate $P C_{F}$. According to Table 2, the $P C_{F}$ of the selected wind turbines can be calculated as follows:

$$
\begin{array}{ll}
P C_{F 1}=\frac{1}{2454.125} V_{m}^{3}-\frac{42.975}{2454.125} & \text { (15) } \\
P C_{F 2}=\frac{1}{2690} V_{m}^{3}-\frac{64}{2690} & \text { (16) }{ }_{P C_{F 3}}=\frac{1}{3349} V_{m}^{3}-\frac{27}{3349}
\end{array}
$$

The relationship between the mean wind speed and capacity factor of different wind turbines is plotted in Fig.1. 


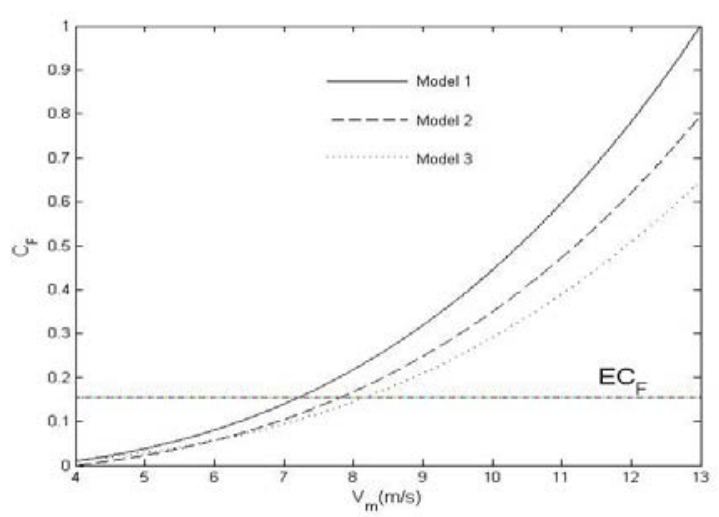

Fig.1 the relationship between wind speed and $C_{F}$

\section{Results and discussion}

Fig.1 shows the difference between $\mathrm{EC}_{\mathrm{F}}$ and $\mathrm{PC}_{\mathrm{F} \text {. }}$ The lowest mean wind speed of each wind turbine is calculated by breakeven analysis. Define this mean wind speed as economic mean wind speed. According to Fig.1, the economic mean wind speed of three wind turbines are $7.21 \mathrm{~m} / \mathrm{s}, 7.81$ $\mathrm{m} / \mathrm{s}$ and $8.16 \mathrm{~m} / \mathrm{s}$ respectively. The wind turbine can be chosen if the actual mean wind speed is higher than the economic mean wind speed of the wind turbine. If the wind speed of all of the wind turbines can't reach the mean wind speed, this site is improper for building a new wind power plant.

The result shows that $\mathrm{EC}_{\mathrm{F}}$ depends on the specific cost of wind turbines, the wages level of the location site and the stake electrovalence of wind energy. $\mathrm{EC}_{\mathrm{F}}$ in different sites is different. $\mathrm{PC}_{\mathrm{F}}$ is related to the performance of wind turbine and the wind speed condition. $\mathrm{PC}_{\mathrm{F}}$ depends on the cut-in speed and rated speed of the wind wind turbine. For same machine, the $\mathrm{PC}_{\mathrm{F}}$ is higher with larger mean wind speed.

\section{Conclusion}

It should be noted that the proposed approach aims at discussing the calculation model of Wind Energy Output. This paper takes wind speed conditions and wind turbine performances into consideration, calculates the ECF and PCF, and obtains the relationship between the mean wind speed and capacity factor. The results of this paper provide a new quantitative basis for wind turbine selections and wind farm location selections.

The effect of the stake electrovalence changing and subsidy policy on capacity factor should be considered as a further study in order to obtain overall conclusion.

\section{Acknowledgements}

This work was financially supported by the Sichuan University founding of National Higher-education Institution General Research and Development Project (skzx2013-dz05).

\section{References}

[1] Wenjun Zhang, Wei Yu.Analysis on Supply and Demand Environment of China's Wind Power Industry and Its Development Forecasting[J]. China Population , Resouse and Environment, 2014,07:106-113; In Chinese

[2] Ali Mostafaeipour, Mohsen Jadidi. An analysis of wind energy potential and economic evaluation in Zahedan, Iran[J]. Renewable and Sustainable Energy Reviews, 2014, 30:641 -650.

[3] Zhang Xu.Installed Capacity Optimization of Wind Turbine Generators Considering Maximum Economic Benefit of Wind Farm [J]. Power System Technology, 2012, 01:237-240. In Chinese 
[4] Li Yongguang.Study on the Selection for the Rated Wind Speedof Wind Turbines [J]. Journal of Shanghai University of Electric Power, 2013, 02:107-110. In Chinese

[5] AkdagSeyit,GülerOnder. Impact of wind speed measurement resolution on estimated capacity factor and electricity production cost [J]. Energy and Environment, 2013, 24:999-1012.

[6] YoonGihwan, LeeHyewon. Power curve of a wind generator suitable for a low wind speed site to achieve a high capacity factor [J]. Journal of Electrical Engineering and Technology, 2014,9: 820-826.

[7] Mohammadi K. Using different methods for comprehensive study of wind turbine utilization in Zarrineh, Iran [J]. Energy Convers Manage, 2013, 65:463-70.

[8] George Caralis, Danae Diakoulaki. Profitability of wind energy investments in China using a Monte Carlo approach for the treatment of uncertainties [J]. Renewable and Sustainable Energy Reviews , 2014,40: 224-236. 